\title{
Randomized control trials testing the efficacy of psychotherapy in individuals at Ultra High Risk for developing psychosis: a review Costas Kollias*, Beata Havaki-Kontaxaki and Melina Kontaxaki
}

\author{
Address: Univerity of Athens, Psychiatric Department, Eginition Hospital, Athens, Greece \\ * Corresponding author
}

\author{
from International Society on Brain and Behaviour: 3rd International Congress on Brain and Behaviour \\ Thessaloniki, Greece. 28 November - 2 December 2007 \\ Published: 17 April 2008 \\ Annals of General Psychiatry 2008, 7(Suppl I):S2 I2 doi:I0.I 186/I744-859X-7-SI-S2 I 2
}

This abstract is available from: http://www.annals-general-psychiatry.com/content/7/SI/S2I2

(c) 2008 Kollias et al.; licensee BioMed Central Ltd.

\section{Background}

In the past ten years an effort has been made to establish clinical criteria, in order to predict which individuals are at ultra high risk (UHR) of developing psychosis. Various preventive and therapeutic methods have been used at people with incipient risk of developing psychosis, psychotherapeutic as well as psychopharmacological. The psychotherapeutic techniques are certainly more appropriate to use in such populations for safety reasons. The goal of our presentation is to find out if there has been sufficient indication of the efficacy of such psychotherapeutic techniques through randomized control trials.

\section{Materials and methods}

We conducted a systematic literature search through the web, for the years 1980-2007, combining key words of "prevention", "ultra high risk", "prodrome", "psychosis", "psychotherapy" and then limited our results to "randomised control trials". We also searched for major metaanalyses and reviews of prevention studies for psychosis.

\section{Results}

Only two randomised control studies were found to be conducted in such populations, searching for the efficacy of cognitive therapy and needs-based supportive psychotherapy.

\section{Conclusions}

Both of them demonstrated that psychotherapy is useful in such groups, since it reduces the likelihood of making progression to psychosis, the need for prescription of antipsychotic medication and has enduring benefits over the long term.

\section{References}

I. Morrison A, French P, Parker S, Roberts M, Stevens H, Bentall R, Lewis $S$ : Three year follow up of a randomized control trial of cognitive therapy for the prevention of psychosis in people at ultrahigh risk. Schizophrenia Bulletin 2007, 33:682-687.

2. McGorry PD, Yung AR, Philips LJ, Yuen HP, Francey S, Cosgrave EM, Germano D, Bravin J, McDonald T, Blair A, Adlard S, Jackson H: Randomized controlled trial of interventions designed to reduce the risk of progression to first-episode psychosis in a clinical sample with subthreshold symptoms. Arch Gen Psychiatry 2002, 59(10):921-928. 